\title{
The impact of parental migration on health status and health behaviours among left behind adolescent school children in China
}

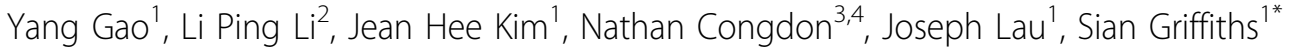

\begin{abstract}
Background: One out of ten of China's population are migrants, moving from rural to urban areas. Many leave their families behind resulting in millions of school children living in their rural home towns without one or both their parents. Little is known about the health status of these left behind children (LBC). This study compares the health status and health-related behaviours of left behind adolescent school children and their counterparts in a rural area in Southern China.
\end{abstract}

Methods: A cross-sectional study was conducted among middle school students in Fuyang Township, Guangdong, China (2007-2008). Information about health behaviours, parental migration and demographic characteristics was collected using a self-administered questionnaire. Overweight/obesity and stunting were defined based on measurements of height and weight. Univariate and multivariate analyses were used to estimate the differences in health outcomes between LBC and non-LBC.

Results: $18.1 \%$ of the schoolchildren had one or both parents working away from home. Multivariate analysis showed that male LBC were at higher risk of skipping breakfast, higher levels of physical inactivity, internet addiction, having ever smoked tobacco, suicide ideation, and being overweight. LBC girls were more likely to drink excessive amounts of sweetened beverage, to watch more TV, to have ever smoked or currently smoke tobacco, to have ever drunk alcohol and to binge drinking. They were also more likely to be unhappy, to think of planning suicide and consider leaving home.

Conclusions: Our findings suggest that parental migration is a risk factor for unhealthy behaviours amongst adolescent school children in rural China. Further research is required in addition to the consideration of the implications for policies and programmes to protect LBC.

\section{Background}

China has been undergoing rapid urbanization in the last few decades. By 2000, over 100 million people in China were migrants [1]. The majority of internal migrants are adults aged 25-49 years old, moving from rural to urban areas to seek employment opportunities $[2,3]$. Children often do not move with their parents due to financial constraints and the transient nature of the work in urban areas [1]. The term "left behind children (LBC)" is ascribed to the children staying in their rural home towns and villages. By 2000, the number of LBC

\footnotetext{
* Correspondence: siangriffiths@cuhk.edu.hk
'School of Public Health and Primary Care, the Chinese University of Hong

* Correspondence: siangriffiths@cuhk.edu.hk
'School of Public Health and Primary Care, the Chinese University of Hong Kong, Hong Kong SAR, China
}

(c) 2010 Gao et al; licensee BioMed Central Ltd. This is an Open Access article distributed under the terms of the Creative Commons Attribution License (http://creativecommons.org/licenses/by/2.0), which permits unrestricted use, distribution, and reproduction in any medium, provided the original work is properly cited.

living in rural areas across China was estimated to be around 20 million, and about $10 \%$ of the LBC population in China live in Guangdong province, which ranks the second highest amongst the 31 provinces in China [1].

Unhealthy behaviours such as smoking tobacco and poor diet during adolescence perpetuate into adulthood and have lasting health impacts $[4,5]$. Evidence from studies in various countries suggests that a stable family environment contributes to healthy development among children [4-10]. Mixed results have however been generated with respect to the health impact of parental migration on the health of LBC [11-16]. Negative impacts such as substance use and poorer psychosocial health have been documented [11-13]. However, some 
Asian studies (including those conducted in India, Pakistan, Sri Lanka, Philippines, and Thailand) have indicated that the actual impact of parental migration on educational and psychological aspects of the LBC is only modest [14-16].

In China studies have reported that LBC encounter more educational problems, such as higher rates of absence and dropout rates $[17,18]$. LBC are also found to be more vulnerable to psychological problems such as loneliness, depression, anxiety, and introversion [19-22]. One study however, found no significant difference in academic performance between LBC and nonLBC living in three Chinese provinces [23]. There is a dearth of data concerning physical health of LBC in China.

In this study, we investigated the impact of parental migration among rural middle school students in Southern China, and explored their nutritional health status (indicated by stunting and overweight/obesity) and health-related behaviours (including eating habits, physical activity, smoking, drinking, internet abuse, and emotional issues). Through comparison with their counterparts in the same rural area whose parents had not migrated we were able to describe the impact of left behind status.

\section{Methods}

\section{Subjects}

A cross-sectional study was conducted between December 2007 and June 2008 in Fuyang Township, Guangdong Province. Fuyang has a population of 87,134 and a per capita annual net income of 5,154 RMB (2008), which compares well with national and provincial mean figures of 4,140 RMB and 5,624 RMB respectively $[24,25]$. The township is categorized as a Type II rural area (Type I is very affluent and Type IV is very poor). There are five junior secondary schools (1 vocational + 4 regular) for children aged 13-15 years old and one senior secondary school for those aged $16-18$ years. All Years 1 and 2 junior and senior secondary school students were invited to join the study. Field investigators assisted students to complete a questionnaire in their classrooms without the presence of teachers. Height and weight were measured in a designated room in each school by two investigators using calibrated scales. All investigators received training in advance. Informed written consent was obtained from the students in advance. Ethics approval was obtained from the Ethics Committees at the Chinese University of Hong Kong.

\section{Measures}

\section{Definition of $L B C$ cases}

In order to be consistent with the national definition of "floating population", this study adopted Zhou and
Duan's definition of LBC as "children under 18 who have been left behind at their original residence while one or both parents migrate into other places for work and have been not living together with them for at least six months" [18]. Students were asked: 1, "Has your father/mother NOT been living with you for at least six months in a row?" and 2, "Why has your father/mother NOT been living with you?". Children who responded "No" to the first question and gave "working" as the reason of separation were identified as LBC. Separation due to divorced/separated or deceased parents did not constitute LBC cases.

\section{Socio-demographic characteristics}

Information about students' ethnicity, gender, age, class, grade, school, whether boarding in the school, as well as education level and occupation of parents, whether living with grandparents, housing type, and annual family income per capita was collected.

\section{Health-related behaviours}

The questions were adapted from those being used in the 2005 Chinese Youth Risk Behaviour Survey (YRBS), the 2007 YRBS of the U.S., and the Global School-based Student Health Survey (GSHS) to develop the questionnaire [26-28]. Questions were related to eating habits, physical activity, sedentary behaviours, internet use, tobacco use, alcohol use, and mental and emotional health. Being physically active was defined as reporting being active at least 60 minutes per day, including the time they spent in any kind of activity that increased their heart rate and made them breathless some of the time [26]. Binge drinking was defined as "ever having had at least five glasses of alcohol within one or two hours in the past 30 days" [26]. Internet addiction was identified using the Youth 8-item Internet Addiction Scale [29].

\section{Nutritional status}

Height and weight were measured and body mass index (BMI, $\mathrm{kg} / \mathrm{m}^{2}$ ) was derived to indicate students' nutritional status. Height (recorded to the nearest $1 \mathrm{~cm}$ ) was measured with bare or stockinged feet. Weight (recorded to the nearest $0.1 \mathrm{~kg}$ ) was measured with the subject lightly dressed. Overweight and obese children were defined according to the Chinese BMI-for-Age cut-off points for children aged 7-18 years old [30]. The World Health Organization (WHO) definition of $<-2$ SD of Height-for-Age $\mathrm{Z}$ scores was used to identify stunted children [31].

\section{Data analysis}

Data was entered through the Remark Office OMR ${ }^{\odot} 6$ (Gravic Inc., Malvern, PA). SPSS for Windows 16.0 (SPSS Inc., Chicago, IL) was used for all statistical analyses. Analyses were stratified by gender. To test statistical significance of between-group differences (e.g. 
LBC versus non-LBC), chi-square and One-way Analysis of Variance tests were used; Odds Ratio (OR) and Mean Difference (MD) and respective 95\% Confidence Intervals (95\% CI) were also derived. Multiple logistic regression and linear regression models were fitted, adjusting for potential confounders including age (adjusted as a continuous variable), ethnicity, school type (regular vs. vocational school), whether living in a boarding school, parental education level, whether living with grandparents, housing type, and whether having computer access at home [32,33]. We did not adjust for parents' occupation because migrant parents of LBC were non-farmer and the health impact due to parental migration would be removed if it is adjusted $[32,33]$. Significance and goodness of fit were tested for each final model [32,33].

\section{Results \\ Participation}

One school was excluded due to lack of interest in participation. This school is a regular junior school and has similar characteristics with the other schools in the study. 5 schools took part in the final study. A total of 3226 students were invited to take part in the study, 3141 (97.4\%) agreed, and 2986 (92.6\%) completed the questionnaire and the measurements and were included in the analysis (91.5\% for boys and $94.2 \%$ for girls respectively).

\section{Socio-demographic characteristics}

$18.1 \%$ (541) of the respondents were LBC. $51.4 \%$ were male and their ages ranged from 10-18 years (mean age $=14.2$ years, median $=14.0$ years $)$. When compared with non-LBC, LBC were more likely to be boys, Year 1 junior secondary school students and their average age was 13.2 years $(\mathrm{SD}=0.63$ years). They were more likely to be from an ethnic minority, and not to be a boarder (Table $1, \mathrm{p}<0.05$ ). In addition, parents of LBC were less likely to be farmers and their mothers were more likely to be highly educated. LBC were less likely to have a computer and internet access at home $(\mathrm{p}<0.05)$. Similar proportions of LBC and non-LBC (69.2\% vs. $70.9 \%, \mathrm{P}>0.05$ ) were unaware of their yearly family income per capita and another $13.5 \%$ refused to answer the question (data not shown), possibly because they did not know.

\section{Comparison of health status and health-related behaviours between LBC and non-LBC}

In general, $\mathrm{LBC}$ had a higher prevalence of all the unhealthy lifestyle behaviours such as smoking but lower rates of all other healthy behaviours with the exception of intake of fruits and milk and participation in sport teams (Table 2). A range of health outcomes
(12 items for boys and 10 for girls) showed significance or were marginally significant before controlling for other factors, and 6 items for boys and 9 for girls reached at least marginal significance in adjusted models (Tables 3 \&4). Overall, children with both parents absent were most likely to engage in risk behaviours (skipping breakfast, eating high-fat food and sweetened snacks, being physically inactive, spending more time watching TV, playing e-games and using internet, current smoking and drinking, and having been drunk). They were also most likely to have emotional and mental problems and to be overweight and stunted. Children with a migrant mother only were also more vulnerable compared to those with father's absence only.

\section{Dietary behaviours and physical activity}

Overall, most students had breakfast everyday (74.3\%) and ate recommended portion of vegetables (59.1\%). Less than one quarter of them consumed high-fat food $(13.8 \%)$, sweetened snacks $(23.4 \%)$ or sweetened beverages $(18.1 \%)$ at least 3 times/day. Very few students felt hungry most of the time $(1.3 \%)$ or drank milk at least 6 days/week (7.4\%). Around half of children reported adequate physical activity levels (49.2\%) although some of them were rather sedentary $(19.0 \%$ watched TV, $15.5 \%$ did homework and $9.3 \%$ played egames for at least 4 hours/day). After adjustment for the confounding factors, left behind boys were marginally less likely to eat breakfast everyday $\left(\mathrm{OR}_{\mathrm{mv}}=0.75\right)$, but significantly less likely to be physically active $\left(O R_{m v}=\right.$ 0.67) (Table 3). The female LBC were more vulnerable to excess drinking of sweetened beverages $\left(\mathrm{OR}_{\mathrm{mv}}=1.50\right.$, $\mathrm{P}=0.082)$ and excess $\mathrm{TV}$ watching $\left(\mathrm{OR}_{\mathrm{mv}}=1.48, \mathrm{P}=\right.$ 0.043) (Table 4).

\section{Internet use, tobacco use and alcohol use}

More than half the students used internet in the past 12 months but few of them admitted to over-use $(6.8 \%)$ or would be defined as internet addicted (5.8\%). Compared to girls, boys were more likely to both smoke tobacco and drink alcohol (Table 2). Most boys had smoked (50.2\%) or drunk alcohol (69.7\%) in their lifetime and current smoking and binge drinking rates were $17.1 \%$ and $12.1 \%$ respectively among boys. In comparison to non-LBC, left behind boys were more likely to be internet addicted and to have ever smoked $\left(\mathrm{OR}_{\mathrm{mv}}=1.39\right.$ 1.77) after controlling for the confounders (Table 3). Left behind girls were at significantly higher risk for ever and current smoking and binge drinking before and after adjustment with confounders, with the highest $\mathrm{OR}_{\mathrm{mv}}$ of 6.58 found for currently smoking (Table 4). In addition, the nonsignificant $\mathrm{OR}_{\text {unadj }}$ of parental migration for ever alcohol use among girls increased and reached marginal significance in the multivariate model $\left(\mathrm{OR}_{\mathrm{mv}}=1.35\right)($ Table 4). 
Table 1 Comparison of demographic characteristics between LBC ${ }^{a}$ and non-LBC

\begin{tabular}{|c|c|c|c|c|}
\hline & $\begin{array}{c}\text { Total } \\
(\mathrm{N}=2986)\end{array}$ & $\begin{array}{c}\text { Non-LBC } \\
(\mathrm{N}=2445)\end{array}$ & $\begin{array}{c}\text { LBC } \\
(\mathrm{N}=541)\end{array}$ & $\begin{array}{l}\text { p-value } \\
\left(\chi^{2} \text { test }\right)\end{array}$ \\
\hline Gender (\%) & & & & 0.075 \\
\hline Male & 51.4 & 50.7 & 54.9 & \\
\hline Female & 48.6 & 49.3 & 45.1 & \\
\hline Age (year), Mean (SD) & $14.2(1.4)$ & $14.3(1.5)$ & $13.7(1.2)$ & $<0.001^{b}$ \\
\hline Ethnicity (\%) & & & & 0.030 \\
\hline Han & 99.4 & 99.5 & 98.7 & \\
\hline Others & 0.6 & 0.5 & 1.3 & \\
\hline Grade (\%) & & & & $<0.001$ \\
\hline Year 1 of junior secondary school & 57.8 & 54.2 & 74.3 & \\
\hline Year 2 of junior secondary school & 19.5 & 20.3 & 15.7 & \\
\hline Year 1 of senior secondary school & 22.7 & 25.5 & 10.0 & \\
\hline Boarder in this term (\%) & & & & $<0.001$ \\
\hline Yes & 12.5 & 13.7 & 6.6 & \\
\hline No & 87.5 & 86.3 & 93.4 & \\
\hline Father's education (\%) & & & & 0.786 \\
\hline Primary school and below & 24.7 & 24.5 & 25.9 & \\
\hline Junior secondary school & 53.0 & 53.2 & 52.0 & \\
\hline Senior secondary school and above & 22.3 & 22.3 & 22.1 & \\
\hline Father's occupation (\%) & & & & 0.008 \\
\hline Farmer & 31.9 & 33 & 26.5 & \\
\hline Non-farmer & 68.1 & 67 & 73.5 & \\
\hline Mother's education (\%) & & & & 0.005 \\
\hline Primary school and below & 56.1 & 57.2 & 51.0 & \\
\hline Junior secondary school & 34.1 & 33.7 & 35.9 & \\
\hline Senior secondary school and above & 9.8 & 9.1 & 13.2 & \\
\hline Mother's occupation (\%) & & & & $<0.001$ \\
\hline Farmer & 47.6 & 50.2 & 35.4 & \\
\hline Non-farmer & 52.4 & 49.8 & 64.6 & \\
\hline Living with grandparents (\%) & & & & 0.608 \\
\hline Yes & 25.9 & 25.7 & 26.8 & \\
\hline No & 74.1 & 74.3 & 73.2 & \\
\hline House type (\%) & & & & 0.352 \\
\hline Single-storey house & 47.0 & 49.3 & 47.4 & \\
\hline Multi-storey house & 53.0 & 50.7 & 52.6 & \\
\hline Having computer at home (\%) & & & & 0.061 \\
\hline No & 68.2 & 67.4 & 72.0 & \\
\hline Yes, but not connected with internet & 12.9 & 13.0 & 12.7 & \\
\hline Yes, already connected with internet & 18.8 & 19.6 & 15.3 & \\
\hline
\end{tabular}


Table 2 Comparison of health behaviours and physical health among LBC ${ }^{\mathrm{a}}$ and non-LBC by gender

\begin{tabular}{|c|c|c|c|c|c|c|}
\hline & \multicolumn{3}{|c|}{ Males } & \multicolumn{3}{|c|}{ Females } \\
\hline & $\begin{array}{c}\text { All } \\
(n=1536)\end{array}$ & $\begin{array}{c}\text { Non-LBC } \\
(n=1239)\end{array}$ & $\begin{array}{c}\text { LBC } \\
(n=297)\end{array}$ & $\begin{array}{c}\text { All } \\
(n=1450)\end{array}$ & $\begin{array}{c}\text { Non-LBC } \\
(n=1206)\end{array}$ & $\begin{array}{c}\text { LBC } \\
(n=244)\end{array}$ \\
\hline \multicolumn{7}{|l|}{ Dietary intake (\%) } \\
\hline Felt hungry most of the time or always ${ }^{1}$ & $1.5 \%$ & $1.2 \%$ & $2.8 \%$ & $1.1 \%$ & $1.2 \%$ & $0.6 \%$ \\
\hline Ate breakfast everyday ${ }^{2}$ & $75.1 \%$ & $76.3 \%$ & $69.4 \%$ & $73.4 \%$ & $73.8 \%$ & $71.1 \%$ \\
\hline Ate vegetables $\geq 3$ times $/$ day $^{2}$ & $61.0 \%$ & $62.5 \%$ & $53.3 \%$ & $57.3 \%$ & $58.0 \%$ & $53.6 \%$ \\
\hline Ate fruits $\geq 3$ times $/$ day $^{2}$ & $39.4 \%$ & $39.2 \%$ & $40.6 \%$ & $37.1 \%$ & $36.0 \%$ & $42.8 \%$ \\
\hline Ate high-fat food $\geq 3$ times $/$ day $^{2}$ & $15.9 \%$ & $15.6 \%$ & $17.8 \%$ & $11.6 \%$ & $11.2 \%$ & $13.9 \%$ \\
\hline Ate sweetened snack $\geq 3$ times/day ${ }^{2}$ & $23.6 \%$ & $23.2 \%$ & $25.6 \%$ & $23.1 \%$ & $22.4 \%$ & $27.1 \%$ \\
\hline Drank sweetened beverage $\geq 3$ times $/$ day ${ }^{2}$ & $24.3 \%$ & $24.4 \%$ & $23.9 \%$ & $11.9 \%$ & $10.9 \%$ & $17.5 \%$ \\
\hline Drank milk $\geq 6$ days/week ${ }^{2}$ & $7.6 \%$ & $7.3 \%$ & $9.4 \%$ & $7.2 \%$ & $7.2 \%$ & $7.2 \%$ \\
\hline \multicolumn{7}{|l|}{ Physical activity \& sedentary behaviours (\%) } \\
\hline Physically active $^{\S} \geq 4$ days/week ${ }^{2}$ & $51.7 \%$ & $53.3 \%$ & $43.9 \%$ & $46.6 \%$ & $46.8 \%$ & $45.8 \%$ \\
\hline Participated in sports team(s) ${ }^{3}$ & $31.1 \%$ & $30.7 \%$ & $33.3 \%$ & $23.7 \%$ & $23.6 \%$ & $24.1 \%$ \\
\hline Watched TV $\geq 4$ hours $/$ day $^{2}$ & $19.3 \%$ & $19.4 \%$ & $18.9 \%$ & $18.7 \%$ & $17.4 \%$ & $25.9 \%$ \\
\hline Did homework $\geq 4$ hours $/$ day $^{2}$ & $11.5 \%$ & $12.5 \%$ & $6.1 \%$ & $19.5 \%$ & $20.1 \%$ & $16.3 \%$ \\
\hline Played electronic games $\geq 4$ hours $/$ day $^{2}$ & $13.5 \%$ & $13.0 \%$ & $16.1 \%$ & $5.1 \%$ & $4.9 \%$ & $6.0 \%$ \\
\hline \multicolumn{7}{|l|}{ Internet use (\%) } \\
\hline Used internet ${ }^{2}$ & $60.2 \%$ & $60.0 \%$ & $61.1 \%$ & $44.7 \%$ & $45.7 \%$ & $39.2 \%$ \\
\hline Used internet $\geq 4$ hours $/$ day $^{2}$ & $9.7 \%$ & $9.5 \%$ & $10.6 \%$ & $3.9 \%$ & $3.9 \%$ & $4.2 \%$ \\
\hline Internet addiction & $8.4 \%$ & $7.7 \%$ & $11.7 \%$ & $3.2 \%$ & $3.3 \%$ & $2.4 \%$ \\
\hline \multicolumn{7}{|l|}{ Tobacco \& alcohol use (\%) } \\
\hline Ever smoked & $50.2 \%$ & $49.3 \%$ & $55.0 \%$ & $10.8 \%$ & $10.0 \%$ & $15.1 \%$ \\
\hline Currently smoked $^{1}$ & $17.1 \%$ & $16.3 \%$ & $20.6 \%$ & $1.0 \%$ & $0.6 \%$ & $3.6 \%$ \\
\hline Ever drank alcohol & $69.7 \%$ & $69.1 \%$ & $72.8 \%$ & $42.7 \%$ & $42.9 \%$ & $41.9 \%$ \\
\hline Currently drank alcohol $^{1}$ & $33.6 \%$ & $32.7 \%$ & $37.8 \%$ & $13.1 \%$ & $12.9 \%$ & $14.5 \%$ \\
\hline Binge drinking"1 & $12.1 \%$ & $11.9 \%$ & $13.3 \%$ & $2.8 \%$ & $2.1 \%$ & $6.6 \%$ \\
\hline Reported symptoms of drunkenness ${ }^{3}$ & $22.6 \%$ & $22.4 \%$ & $23.9 \%$ & $10.2 \%$ & $10.0 \%$ & $11.4 \%$ \\
\hline \multicolumn{7}{|l|}{ Emotional and mental issues (\%) } \\
\hline Felt lonely most of the time or always ${ }^{3}$ & $4.9 \%$ & $4.6 \%$ & $6.7 \%$ & $6.9 \%$ & $6.8 \%$ & $7.8 \%$ \\
\hline Felt unhappy most of the time or always ${ }^{3}$ & $13.8 \%$ & $13.7 \%$ & $14.4 \%$ & $16.8 \%$ & $16.3 \%$ & $19.3 \%$ \\
\hline Sleepless most of the time or always ${ }^{3}$ & $5.7 \%$ & $5.4 \%$ & $7.2 \%$ & $6.3 \%$ & $6.2 \%$ & $6.6 \%$ \\
\hline Felt sad or hopeless $\geq 2$ weeks $^{3}$ & $8.6 \%$ & $8.3 \%$ & $10.0 \%$ & $10.3 \%$ & $10.2 \%$ & $10.8 \%$ \\
\hline Suicide ideation $^{3}$ & $6.3 \%$ & $5.4 \%$ & $11.1 \%$ & $11.0 \%$ & $10.3 \%$ & $15.1 \%$ \\
\hline Suicide plan $^{3}$ & $1.3 \%$ & $1.1 \%$ & $2.2 \%$ & $2.0 \%$ & $1.6 \%$ & $4.2 \%$ \\
\hline Suicide attempt ${ }^{3}$ & $0.7 \%$ & $0.6 \%$ & $1.7 \%$ & $1.2 \%$ & $1.0 \%$ & $2.4 \%$ \\
\hline Ideation of leaving home ${ }^{3}$ & $14.0 \%$ & $13.1 \%$ & $18.3 \%$ & $14.1 \%$ & $13.3 \%$ & $18.7 \%$ \\
\hline Attempt of leaving home ${ }^{3}$ & $2.1 \%$ & $2.0 \%$ & $2.8 \%$ & $0.7 \%$ & $0.4 \%$ & $2.4 \%$ \\
\hline \multicolumn{7}{|l|}{ Nutritional health (\%) } \\
\hline Overweight & $6.2 \%$ & $5.2 \%$ & $11.1 \%$ & $4.7 \%$ & $4.5 \%$ & $5.4 \%$ \\
\hline Obese & $1.7 \%$ & $1.6 \%$ & $2.2 \%$ & $0.9 \%$ & $0.9 \%$ & $1.2 \%$ \\
\hline Stunted & $6.2 \%$ & $5.8 \%$ & $8.3 \%$ & $4.4 \%$ & $4.5 \%$ & $3.6 \%$ \\
\hline
\end{tabular}


Table 2: Comparison of health behaviours and physical health among LBC and non-LBC by gender (Continued)

\begin{tabular}{lcccccc}
\hline & Mean $\pm S D^{4}$ & Mean $\pm S D^{4}$ & Mean $\pm S D^{4}$ & Mean $\pm S D^{4}$ & Mean $\pm S D^{4}$ & Mean $\pm S D^{4}$ \\
\hline Height $(\mathrm{cm})$ & $160.5 \pm 9.2$ & $161.0 \pm 9.2$ & $158.3 \pm 8.8$ & $153.7 \pm 5.3$ & $153.9 \pm 5.4$ & $152.9 \pm 5.2$ \\
\hline Weight $(\mathrm{kg})$ & $47.9 \pm 9.9$ & $48.1 \pm 9.8$ & $47.1 \pm 10.4$ & $44.2 \pm 6.8$ & $44.4 \pm 6.8$ & $43.2 \pm 6.8$ \\
\hline BMl $\left(\mathrm{kg} / \mathrm{m}^{2}\right)$ & $18.4 \pm 2.7$ & $18.4 \pm 2.7$ & $18.6 \pm 2.9$ & $18.7 \pm 2.5$ & $18.7 \pm 2.5$ & $18.5 \pm 2.5$ \\
\hline
\end{tabular}

a: LBC: Left Behind Children; Totals for all categories may not sum to1536 (for boys) or 1450 (for girls) due to missing data;

1: in the past 30 days; 2 : in the past 7 days; 3: in the past 12 months; 4: SD: Standard Deviation;

$\S$ : Physically active represents children who were physically active for a total of at least 60 minutes per day, including all the time they spent in any kind of physical activity that increased their heart rate and made their breaths hard some of the time;

"Binge drinking: ever drank at least 5 glasses of alcohol within 1 or 2 hours in the past 30 day.

\section{Emotional and mental issues}

The most common emotional problem among the students was unhappiness (15.3\% felt unhappy always or most of the time in the past 12 months), and $9.4 \%$ expressed sadness. In addition, $8.7 \%$ and $14.1 \%$ had ever had ideations of suicide or leaving home respectively. More girls suffered from emotional issues than boys (Table 2). Left behind boys were more vulnerable to sadness and variables related to suicide and leaving home, but only ideas of suicide $\left(\mathrm{OR}_{\mathrm{mv}}=2.23\right)$ achieved significance in the adjusted model (Table 3). Among girls, the unadjusted analyses revealed that LBC were more likely to report unhappiness and attempts to leaving home $\left(\mathrm{OR}_{\text {unadj }}=1.52-3.96\right)$, whilst the adjusted ORs showed that female LBC were at least marginally more likely to report unhappiness, ideas of suicide and thoughts of leaving home $\left(\mathrm{OR}_{\mathrm{mv}}=1.50-2.24\right)$ (Table 4).

Nutritional health status

The mean values of height and weight were $160.5 \mathrm{~cm}$ and $47.9 \mathrm{~kg}$ for boys and $153.7 \mathrm{~cm}$ and $44.2 \mathrm{~kg}$ for girls

Table 3 Unadjusted and adjusted Odds Ratio (OR) of parental migration among boys (with either $\mathrm{OR}_{\mathrm{unadj}}$ or $\mathrm{OR}_{\mathrm{mv}}$ significant or marginally significant)

\begin{tabular}{|c|c|c|c|c|c|c|}
\hline & \multicolumn{6}{|c|}{$\begin{array}{c}\text { Males } \\
\text { (non-LBC = ref) }\end{array}$} \\
\hline & OR $_{\text {unadj }}$ & $(95 \% \mathrm{Cl})$ & p-value & $\mathrm{OR}_{\mathrm{mv}}$ & $(95 \% \mathrm{Cl})$ & p-value \\
\hline \multicolumn{7}{|l|}{ Dietary intake } \\
\hline Felt hungry most of the time or always ${ }^{1}$ & 2.35 & $(1.07-5.15)$ & 0.028 & 1.31 & $(0.43-3.95)$ & 0.633 \\
\hline Ate breakfast everyday ${ }^{2}$ & 0.75 & $(0.56-0.99)$ & 0.044 & 0.75 & $(0.53-1.05)$ & 0.096 \\
\hline \multicolumn{7}{|l|}{ Physical activity \& sedentary behaviours } \\
\hline Physically active $^{\S} \geq 4$ days/week ${ }^{2}$ & 0.61 & $(0.47-0.78)$ & $<0.001$ & 0.67 & $(0.50-0.92)$ & 0.012 \\
\hline Did homework $\geq 4$ hours/day ${ }^{2}$ & 0.66 & $(0.42-1.02)$ & 0.062 & 0.67 & $(0.40-1.14)$ & 0.137 \\
\hline Played electronic games $\geq 4$ hours $/$ day $^{2}$ & 1.35 & $(0.96-1.90)$ & 0.083 & 1.41 & $(0.93-2.16)$ & 0.110 \\
\hline \multicolumn{7}{|l|}{ Internet use } \\
\hline Internet addiction & 1.83 & $(1.21-2.78)$ & 0.004 & 1.77 & $(1.06-2.95)$ & 0.029 \\
\hline \multicolumn{7}{|l|}{ Tobacco \& alcohol use } \\
\hline Ever smoked & 1.20 & $(0.93-1.55)$ & 0.167 & 1.39 & $(1.02-1.90)$ & 0.037 \\
\hline Currently smoked $^{1}$ & 1.31 & $(0.96-1.80)$ & 0.093 & 1.37 & $(0.92-2.05)$ & 0.118 \\
\hline \multicolumn{7}{|l|}{ Emotional and mental issues } \\
\hline Felt sad or hopeless $\geq 2$ weeks $^{3}$ & 1.89 & $(1.20-2.97)$ & 0.006 & 1.17 & $(0.71-1.96)$ & 0.537 \\
\hline Suicide ideation $^{3}$ & 2.10 & $(0.84-5.26)$ & 0.094 & 2.32 & $(1.33-4.04)$ & 0.003 \\
\hline Suicide attempt ${ }^{3}$ & 1.37 & $(0.97-1.94)$ & 0.072 & 0.50 & $(0.08-3.38)$ & 0.480 \\
\hline \multicolumn{7}{|l|}{ Nutritional health } \\
\hline \multirow[t]{2}{*}{ Overweight } & 2.17 & $(1.39-3.37)$ & $<0.001$ & 1.76 & $(0.96-3.25)$ & 0.069 \\
\hline & \multicolumn{2}{|c|}{$M D_{\text {unadj }}{ }^{4}$} & \multicolumn{4}{|c|}{$M D_{\mathrm{mv}}{ }^{4}$} \\
\hline Mean Height $(\mathrm{cm})$ & -2.51 & $(-3.71-1.30)$ & $<0.001$ & -0.61 & $(-1.75-0.54)$ & 0.298 \\
\hline
\end{tabular}

1: in the past 30 days; 2 : in the past 7 days; 3 : in the past 12 months; 4 : MD: Mean Difference $=($ mean for LBC) - (mean for non-LBC);

$\S:$ Physically active represents children who were physically active for a total of at least 60 minutes per day, including all the time they spent in any kind of physical activity that increased their heart rate and made their breaths hard some of the time;

Adjusted models were fitted after controlling age, ethnicity, school type, boarder, parental education level, living with grandparents, house type, and computerowning at home (for internet addiction only). 
Table 4 Unadjusted and adjusted Odds Ratio (OR) of parental migration among girls (with either $\mathrm{OR}_{\mathrm{unadj}}$ or $O \mathrm{R}_{\mathrm{mv}}$ significant or marginally significant)

\begin{tabular}{|c|c|c|c|c|c|c|}
\hline & \multicolumn{6}{|c|}{$\begin{array}{c}\text { females } \\
\text { (non-LBC = ref) }\end{array}$} \\
\hline & OR $_{\text {unadj }}$ & $(95 \% \mathrm{Cl})$ & p-value & $\mathrm{OR}_{\mathrm{mv}}$ & $(95 \% \mathrm{Cl})$ & p-value \\
\hline \multicolumn{7}{|l|}{ Dietary intake } \\
\hline Ate vegetables $\geq 3$ times $/$ day $^{2}$ & 0.76 & $(0.57-1.00)$ & 0.048 & 0.79 & $(0.57-1.08)$ & 0.143 \\
\hline Drank sweetened beverage $\geq 3$ times/day ${ }^{2}$ & 1.54 & $(1.05-2.25)$ & 0.028 & 1.50 & $(0.95-2.37)$ & 0.082 \\
\hline \multicolumn{7}{|l|}{ Physical activity \& sedentary behaviours } \\
\hline Watched TV $\geq 4$ hours/day ${ }^{2}$ & 1.71 & $(1.24-2.36)$ & 0.001 & 1.48 & $(1.01-2.17)$ & 0.043 \\
\hline \multicolumn{7}{|l|}{ Internet use } \\
\hline Used internet $^{2}$ & 0.74 & $(0.55-0.99)$ & 0.039 & 1.05 & $(0.72-1.54)$ & 0.791 \\
\hline \multicolumn{7}{|l|}{ Tobacco \& alcohol use } \\
\hline Ever smoked & 1.46 & $(0.98-2.16)$ & 0.060 & 1.88 & $(1.19-2.96)$ & 0.007 \\
\hline Currently smoked $^{1}$ & 6.07 & $(2.02-18.24)$ & 0.002 & 6.58 & $(2.00-21.69)$ & 0.002 \\
\hline Ever drank & 0.96 & $(0.72-1.28)$ & 0.786 & 1.35 & $(0.97-1.87)$ & 0.078 \\
\hline Binge drinking ${ }^{11}$ & 2.74 & $(1.49-5.02)$ & 0.001 & 2.64 & $(1.30-5.37)$ & 0.007 \\
\hline \multicolumn{7}{|l|}{ Emotional and mental issues } \\
\hline Felt unhappy most of the time or always ${ }^{3}$ & 1.52 & $(1.08-2.15)$ & 0.017 & 1.80 & $(1.20-2.68)$ & 0.004 \\
\hline Suicide plan $^{3}$ & 1.84 & $(0.81-4.18)$ & 0.140 & 2.24 & $(0.91-5.56)$ & 0.081 \\
\hline Ideation of leaving home ${ }^{3}$ & 1.34 & $(0.93-1.95)$ & 0.120 & 1.50 & $(0.99-2.26)$ & 0.055 \\
\hline Attempt of leaving home ${ }^{3}$ & 3.96 & $(1.46-10.73)$ & 0.010 & 2.92 & $(0.79-10.81)$ & 0.109 \\
\hline Nutritional health & \multicolumn{2}{|c|}{$M D_{\text {unadj }}{ }^{4}$} & \multicolumn{4}{|c|}{$M D_{\mathrm{mv}}{ }^{4}$} \\
\hline Mean Height (cm) & -1.10 & $(-1.84-0.36)$ & 0.004 & -0.29 & $(-1.10-0.51)$ & 0.476 \\
\hline
\end{tabular}

1: in the past 30 days; 2 : in the past 7 days; 3 : in the past 12 months; 4: MD: Mean Difference = (mean for LBC) - (mean for non-LBC);

"Binge drinking: ever drank at least 5 glasses of alcohol within 1 or 2 hours in the past 30 day;

Adjusted models were fitted after controlling age, ethnicity, school type, boarder, parental education level, living with grandparents, house type, and computerowning at home (for internet use only).

(a mean age of 14.2 years for both genders) (Table 2). After controlling for potential confounders, the significant differences in mean height between LBC and nonLBC for both genders decreased and became nonsignificant (Tables 3 \&4). Compared to girls, more boys had unhealthy weight $(6.2 \%$ overweight, $1.7 \%$ obesity and $6.2 \%$ stunting) (Table 2). The significant higher risk for overweight among left behind boys slightly decreased and became marginally significant after adjustment for the confounders $\left(\mathrm{OR}_{\mathrm{mv}}=1.76\right)$ (Table 3). Left behind girls were more vulnerable to obesity, but the ORs failed to achieve significance in both unadjusted and adjusted models (Table 4).

\section{Discussion and Conclusion}

This cross-sectional study may be the first to explore the health impact of parental migration on the children they leave behind in rural China. Around one out of five children in the schools studied were identified as LBC and for nearly half of them both parents had migrated to work away from home. Our findings suggest that adolescent LBC are more likely to have a less healthy diet and lower rates of physical activity, to be more likely to be engaged in excessive computer-related activities, use substances such as smoking tobacco and to be overweight. In addition, the health impact of parental migration varies by gender. Girls are more likely to use substances and have emotional problems and express sadness, whilst left behind boys are more vulnerable to being overweight and addicted to the internet. One potential explanation could be the absence of parents but this needs further exploration since the impact of parental migration may be mitigated by having support from extended family members [14-16]. Another contributing factor could be the additional income from remittances from absent parents which contributes to greater affluence and higher standards of living [14-16].

The dynamics between parental migration and the impact on their children's health may contribute via indirect pathways to LBC health, for example through increased family income [14]. However, many students were unable to complete the part of the questionnaire asking about family income so we were not able to examine the relationship between family income and LBC behaviours. Housing type was used as a proxy for socioeconomic status and more LBC lived in multi- 
storey housing, possibly indicating greater family affluence in this part of China. National data has shown that income levels are higher for migrants than their rural counterparts [2]. In China, rising affluence has also been shown to increase unhealthy behaviours and contribute to overweight and obesity, since children with higher family incomes are more likely to have opportunities for unhealthy choices [34-36].

Our findings may corroborate previous reports that LBC are more likely to drop out of school $[18,20]$. The proportions of LBC decreased significantly from $23.3 \%$ in Year 1 junior secondary school students to $8.8 \%$ in Year 1 senior secondary school students. The decrease was much greater among left behind girls, suggesting that left behind girls tended to drop out earlier than their male counterparts $[1,17]$. These findings need further research but suggest that despite the better education of the majority of their parents and the assumed greater affluence, LBC adolescents might be at higher risk of not attaining their educational potential and also of health damaging behaviours.

Similar to previous studies, we observed a higher prevalence of smoking and drinking amongst rural adolescents compared to their urban counterparts [26,37]. Insufficient public awareness, lack of health education and promotion programmes, insufficient implementation of related regulations (e.g. prohibition of selling cigarettes to children under 18 and smoking in public places), and lack of support to help children to quit smoking and drinking in rural areas may contribute to the situation [38]. Evidence has shown that the majority of smokers start smoking before the age of 18, and the younger children are when they first try smoking, the more likely they are to become regular tobacco users and the less likely they are to quit [39]. In addition, we found that rural $\mathrm{LBC}$ are more vulnerable to substance use than non-LBC. Female LBC are 6 times more likely to currently smoke after adjustment for other risk factors. A systematic review on adolescent smoking in China revealed that parents' attitude towards the smoking behaviour of their children is the fourth leading determinant, following gender, teacher smoking, and peer smoking [40]. It may be that the lack of parents' presence is an explanation of the increased vulnerability to tobacco use among LBC. As a result, there is an urgent need to implement effective interventions in rural China with a focus on LBC to both stop adolescents from starting to smoke and to support them in quitting smoking. In addition, given more than $60 \%$ of Chinese adolescents live in rural areas, this would also contribute to decreasing the national smoking prevalence in the future.

Our study confirmed the evidence that emotional problems were more serious among adolescent LBC
$[18,20,21]$. Stable family circumstance helps to promote psychological development of children and adolescents $[4,20]$. Parental migration results in LBC being cared for by other family members such as grandparents [20]. The differences in family role, education level, lifestyle between parents and other caretakers may contribute to an unfavorable environment for psychological development for adolescent LBC [21]. For instance, in China many migrating parents leave their children with grandparents; research has indicated that they may either spoil the children or fail to give them enough emotional care [18-21,23]. In our study, we found that living with grandparents is a risk factor for some health outcomes and such relationships achieved statistical significance or marginal significance in multivariate models for unhappiness $\left(\mathrm{OR}_{\mathrm{mv}}=1.36, \mathrm{P}=0.091\right)$, suicide plan $\left(\mathrm{OR}_{\mathrm{mv}}=\right.$ 3.12, $\mathrm{P}=0.054)$, attempts to leave home $\left(\mathrm{OR}_{\mathrm{mv}}=2.03\right.$, $\mathrm{P}=0.088$ ), as well as having felt hungry and skipping breakfast amongst boys (none for girls, data not shown). This may be due to grandparents being too old to have energy to give enough care to LBC or due to many grandparents receiving less formal education and taking a traditional "out-of-date" view on life, making it more difficult for LBC adolescents to adapt to a rapidly changing society and thereby contributing to the development of emotional problems [18-21,23].

Our study has several limitations. Firstly, it is a crosssectional study, and therefore cannot be used to interpret cause-effect relationship. All of the demographic and behavioural data were self-reported by the students which may lend itself to reporting bias (such as underreporting of stigmatising behaviours or over-reporting healthy behaviours). In order to minimize reporting bias, the students were asked to complete the questionnaire in class in their teachers' absence and anonymity of the study was stressed by investigators. The adopted YRBS and GSHS questionnaires have been shown to have acceptable validity and reliability $[26,41,42]$. Furthermore, it is unlikely that the reporting of health behaviours is systematically different between LBC and nonLBC, and therefore any bias may be not a major threat to our findings on the health impact of parental migration. Parental behaviours may play a role in the behaviour establishment among children. We did not collect information on this aspect in order to keep the questionnaire to an acceptable length. Given at least one of both parents of LBC are not living with them, the health impact of parental behaviours on adolescent LBC may be less than non-LBC. The type of parental migration (e.g. single or both parents' absence) may play a role in the health impact on LBC. However, our study has insufficient power to examine this hypothesis. Some factors such as the time length of parents being away from home and their communication with LBC may also 
contribute to the health impact of migration on LBC. Such information was not collected due to the limit of the length of questionnaire. Finally, this study was conducted only in a rural area of Southern China which may limit the generalisability of the results across China. In addition, this study was not able to cover the estimated $10 \%$ of rural children who are not enrolled in schools.

In summary, our study provides preliminary evidence that left-behind school children in rural Southern China are a vulnerable group who engage in higher rates of unhealthy behaviours and are likely to be overrepresented among both overweight and stunted groups. Parental migration appears to have a greater influence on girls in terms of substance use and mental health problems. Further studies are needed to explore the pathways and mechanisms by which the effect of parental migration impacts on LBC. Our findings have implications for prevention policies and programmes to promote healthy behaviours and improve health status among adolescent LBC in China and other developing countries facing similar internal migration issues.

\section{Acknowledgements}

This work was supported by the Oxford University Li Ka Shing Foundation [BXRMXT0-004]. We are grateful to those students and staff of Medical College of Shantou University (MCSU), Joint Shantou International Eye Centre (JSIEC), and the Chinese University of Hong Kong (CUHK) who helped in data collection and data entry, especially Yao Gui Lu and Yan Ru Ye of the MCSU, Zhen Ling Xie and Jia Si Wu of the JSIEC, and Jasmine Lam and Johnson Lau of the CUHK.

\section{Author details}

'School of Public Health and Primary Care, the Chinese University of Hong Kong, Hong Kong SAR, China. ${ }^{2}$ Injury Prevention Research Center, Medical College of Shantou University, Shantou, China. ${ }^{3}$ Department of Ophthalmology, Faculty of Medicine, the Chinese University of Hong Kong, Hong Kong SAR, China. ${ }^{4}$ Joint Shantou International Eye Centre, Shantou, China.

\section{Authors' contributions}

SG conceived and supervised the study and helped write the manuscript. YG completed the analyses and led the writing. LPL, JHK and JL led the revising. NC assisted with implementing the study. All authors have read and approved the manuscript.

\section{Competing interests}

The authors declare that they have no competing interests.

Received: 7 September 2009

Accepted: 3 February 2010 Published: 3 February 2010

\section{References}

1. Duan CR, Zhou FL: Studies on left behind children in China [in Chinese]. Population Research 2005, 29:29-36.

2. Hu X, Cook S, Salazar MA: Internal migration and health in China. The Lancet 2008, 372:1717-9.

3. Keung Wong DF, Li CY, Song HX: Rural migrant workers in urban China: living a marginalised life. International Journal of Social Welfare 2007, 16:32-40.

4. Riesch SK, Anderson LS, Krueger HA: Parent-child communication processes: preventing children's health-risk behavior. I Spec Pediatr Nurs 2006, 11:41-56.
5. Spear HJ, Kulbok PA: Adolescent health behaviors and related factors: a review. Public Health Nurs 2001, 18:82-93.

6. Benton D: Role of parents in the determination of the food preferences of children and the development of obesity. Int J Obes 2004, 28:858-69.

7. Capron C, Therond C, Duyme M: Brief report: effect of menarcheal status and family structure on depressive symptoms and emotional/ behavioural problems in young adolescent girls. J Adolesc 2007, 30:175-9.

8. Piko BF, Fitzpatrick KM: Socioeconomic status, psychosocial health and health behaviours among Hungarian adolescents. Eur J Public Health 2007, 17:353-60.

9. Griesbach $D, A m o s ~ A$, Currie $C$ : Adolescent smoking and family structure in Europe. Soc Sci Med 2003, 56:41-52.

10. Wang J, Hughes J, Murphy GT, Rigby JA, Langille DB: Suicidal behaviours among adolescents in northern Nova Scotia. Can J Public Health 2003, 94:207-11.

11. McKay L, Macintyre S, Ellaway A: Migration and health: a review of the international literature MRC Social and Public Health Sciences Unit, Occasional Paper no. 12. Glasgow: MRC Social and Public Health Unit 2003.

12. D'Emilio AL, Cordero B, Bainvel B, Skoog C, Comini D, Gough J, et al: The Impact of International Migration: Children left behind in selected countries of Latin America and the Caribbean United Nations Children's Fund (UNICEF), New York 2007.

13. Abbasi N, Irfan M: "Socioeconomic Effects of International Migration on Pakistani Families Left Behind". Asian Labor Migration: Pipeline to the Middle East Boulder, Colorado: Westview PressArnold F, Shah N 1986.

14. Battistella G, Conaco MCG: The Impact of Labour Migration on the Children Left Behind: A Study of Elementary School Children in the Philippines. SOJOURN: Journal of Social Issues in Southeast Asia 1998, 13:220-41 http://www.articlearchives.com/education-training/educationsystems-institutions/1522844-1.html, (19 Jan, 2009).

15. Stevens GWJM, Vollebergh WAM: Mental health in migrant children. Journal of Child Psychology \& Psychiatry 2008, 49(3):276-94.

16. Scalabrini Migration Center: Hearts Apart: Migration in the Eyes of Filipino Children. Episcopal Commission for the Pastoral Care of Migrants and Itinerant People-CBCP/Apostleship of the Sea-Manila, 2005. 2009http:// www.smc.org.ph/heartsapart/cover.htm.

17. Lu DP: Issues and challenges of the left-behind children: based on results of the specific investigation undertaken by China Youth University of Political Sciences [in Chinese]. US-China Education Review 2006, 3:1-9.

18. Zhou FL, Duan CR: Literature review on studies on left behind children [in Chinese]. Population Research 2006, 3:60-65.

19. Gao WB, Wang T, Liu ZK, Wang XL: A study on depression characteristics and its influencing factors in children left in rural areas [in Chinese]. Chin J of Behavioral Med Sci 2007, 16:238-240.

20. Huang XN, Wu J, Peng AN, Li Z, Qi XB, Shi SH: Left behind children, a group of vulnerable population [in Chinese]. Medicine and Society 2005, 18(2):5-6.

21. Wang LF, Zhang S, Sun YH, Zhang XJ: The current situation of loneliness of left behind children in countryside [in Chinese]. Chin J of Behavioral Med Sci 2006, 15:639-640.

22. Zhang $S$, Wang LF, Sun YH, Chen XF, Zhang XJ, Gao R, Xing XY: Epidemiological survey on the current situation of social anxiety of leftbehind children in primary school [in Chinese]. Modern Preventive Medicine 2007, 34:441-443.

23. Zhu KR, Li CJ, Zhou SQ: Analysis and Suggestions to the Learning of the Children who Stay at Home when their Parents are out [in Chinese]. Education Science 2002, 4:21.

24. Agriculture Department of Chaoan County, Chaozhou City, Guangdong Province, China: Statistics of Local Rural Working 2009 [in Chinese].

25. National Bureau of Statistics of China: China statistical yearbook 2008 China Statistics Press 2008http://www.stats.gov.cn/tjsj/ndsj/2008/indexeh.htm.

26. Ji CY: Chinese Youth Risk Behavior Survey report 2005 [in Chinese] Peking University Medical Press, Beijing 2007.

27. Youth Risk Behavior Surveillance of US: 2007 Middle School Youth Risk Behavior Survey Questionnaire http://www.cdc.gov/HealthyYouth/yrbs/.

28. WHO: WHO Global School-based Student Health Survey questionnaire http:// www.who.int/chp/gshs/en/.

29. Young KS: Caught in the Net: how to recognize the signs of internet addiction and a winning strategy for recovery New York, US: John Wiley \& Sons 1998. 
30. Cooperative Meta-analysis Group of China Obesity Task Force: Predictive values of body mass index and waist circumference to risk factors of related diseases in Chinese adult population [in Chinese]. Chinese Journal of Epidemiology 2002, 23(1):5-10.

31. WHO: Growth reference data for 5-19 years http://www.who.int/growthref/ en/.

32. Katz MH: Multivariable analysis: a practical guide for clinicians Cambridge, UK: Cambridge University Press 1999.

33. Glantz SA: Primer of biostatistics New York, US: McGraw-Hill, Medical Pub. Division 2002.

34. Tao FB, Gao M, Wei G, Li YY, Zhang JX, Su PY: Demographic Characteristics of Health2risk Behaviors Among Middle School Students in Hefei [in Chinese]. Chin J School Health 2003, 24(6):571-573.

35. Jiang TT, Lu R, Zhang JX: Survey of risk behavior relevant to health and influential factors in children of two cities in Sichuan Province [in Chinese]. China Tropical Medicin 2006, 143(14):164-165.

36. Ji CY, Sun $J$, Chen TQ: Dynamic analysis on the prevalence of obesity and overweight school-age children and adolescents in recent 15 years in China [in Chinese]. Chinese Journal of Epidemiology 2004, 25:103-8.

37. Sun YH, Yu TS, Tong SL, Zhang Y, Shi XM, Li W: A cross-sectional study of health-related behaviors in rural eastern China. Biomed Environ Sci 2002, 15:347-54.

38. Mao Z, Wu B: Urban-rural, age and gender differences in health behaviours in the Chinese population: findings from a survey in Hubei, China. Public Health 2007, 121:761-4.

39. WHO: Tobacco-free Youth 2009http://www.who.int/tobacco/wntd/2008/flyer/ en/.

40. Han MY, Chen WP: Meta-analysis on the risk factors of adolescent smoking in China. J Adolesc Health Chinese Journal of Disease Control \& prevention 2004, 8:227-30.

41. Brener ND, Billy JOG, Grady WR: Assessment of factors affecting the validity of self-reported health-risk behavior among adolescents: evidence from the scientific literature. Journal of Adolescent Health 2003, 33:436-457.

42. Brener ND, Kann L, McManus TL, Kinchen S, Sundberg EC, Ross JG: Reliability of the 1999 Youth Risk Behavior Survey Questionnaire. Journal of Adolescent Health 2002, 31:336-342.

\section{Pre-publication history}

The pre-publication history for this paper can be accessed here:http://www biomedcentral.com/1471-2458/10/56/prepub

doi:10.1186/1471-2458-10-56

Cite this article as: Gao et al: The impact of parental migration on health status and health behaviours among left behind adolescent school children in China. BMC Public Health 2010 10:56.

\section{Submit your next manuscript to BioMed Central and take full advantage of:}

- Convenient online submission

- Thorough peer review

- No space constraints or color figure charges

- Immediate publication on acceptance

- Inclusion in PubMed, CAS, Scopus and Google Scholar

- Research which is freely available for redistribution

Submit your manuscript at www.biomedcentral.com/submit
Biomed Central 